\title{
Chronic lower limb lymphedema: A single-center epidemiological study
}

\author{
Rifat Özmen $\odot$, Yiğit Akçalı@ \\ Department of Cardiovascular Surgery, Erciyes University, School of Medicine, Kayseri, Turkey
}

\begin{abstract}
Objectives: This study aims to analyze patients with chronic lower limb lymphedema (LE) clinically, diagnostically and etiopathogenetically. Patients and methods: This single-center, retrospective national epidemiological study included a total of 558 patients (161 males, 397 females; median age: 43 years; range, 10 days to 94 years) with chronic lower limb LE who were treated in our department between January 2005 and January 2020. Primary and secondary LE were classified clinically by stage and severity and lymphoscintigraphically. Body mass index was calculated for the detection and classification of obesity.

Results: A total of $72.5 \%$ of the patients had unilateral lower limb LE, while $27.5 \%$ had bilateral LE including lipolymphedema. The rate of the patients with obesity and pre-obesity was $71.2 \%$. Primary LE patients (54.1\%) were more common than those with secondary LE. The rates of clinical, clinical severity, and lymphoscintigraphic staging were $11.1 \%$, 38\%, and 28\%, respectively for Stage I, 55.2\%, 30.9\%, and $42 \%$, respectively for Stage II, and 33.7\%, 31.1\%, and 17\%, respectively for Stage III. Complications were elephantiasis (13.3\%), elephantiasis nostras verrucosa (3.0\%), cellulitis (22.1\%), erysipelas (2.3\%), ulcer (2.6\%), onychomycosis (27.4\%), and lymphangiosarcoma (0.2\%).

Conclusion: Chronic LE is a challenging problem with poor quality of life, negative psychosocial effects, and disabling consequences, and it is of vital importance to recognize the disease in its early stages with awareness, diagnosis, and multidisciplinary approach.
\end{abstract}

Keywords: Complications, etiopathogenesis, lymphedema, lymphoscintigraphy, obesity.

Lymphedema (LE) is a major burden on the health system of all countries, as it is chronic and almost incurable. Although the exact prevalence is unknown, LE, which may affect approximately quarter billion persons world-wide, is a common condition. ${ }^{[1-3]}$ The prevalence of LE in the Europe is estimated to be between 1.33 and 1.44 per 1,000 population. $^{[4,5]}$ The true rate of LE is unknown, as patients with occult or mild disease cannot seek treatment. Most individuals with LE have a secondary disease (prevalence 1/1,000 individuals); primary LE is rare (prevalence $1 / 100,000$ individuals). ${ }^{[6]}$ Among non-cancer-related LEs, $28 \%$ are diagnosed with primary LE. ${ }^{[7]}$ When listed from most prevalent to least common, LE is ranked epidemiologically as filariasis, inguinal lymphadenectomy and/or irradiation and obesity (for secondary LE), and as with pediatric-onset (infant, adolescent, childhood, respectively) and with adult-onset (for primary LE). ${ }^{[5,8,9]}$ Genital LE is usually associated with lower limb LE (isolated vs. plus lower limb: $4.3 \%$ vs. $13.8 \%$, respectively). ${ }^{[8]}$

Lymphedema, defined as edema that develops as a result of insufficient lymphatic drainage, has long been a neglected healthcare field, as it is thought to be a rare, non-fatal and incurable condition that causes little morbidity. Therefore, there has not been enough investment in research on the diagnosis and management of LE, except for those arising from cancer treatment in developed countries. However, currently, this has begun to change with the worldwide prevalence and effect of LE, which increases with underlying obesity (obesity-induced LE), chronic venous disease (phlebolymphedema) and increasing

Received: March 17, 2021 Accepted: April 06, 2021 Published online: April 28, 2021

Correspondence: Yiğit Akçalı, MD. Erciyes Üniversitesi Tıp Fakültesi Kalp ve Damar Cerrahisi Anabilim Dalı, 38030 Melikgazi, Kayseri, Türkiye. e-mail: yigitakcali@gmail.com 
immobility with age. ${ }^{[10]}$ Since cancer-related LE is currently considered to account for only a small proportion of the total cases, these cases including insufficient lymphatic drainage with significant morbidity should be included in the prevalence studies. However, more data on the prevalence, causes and effects of LE are needed to persuade national health authorities to treat current situation and provide resources to reduce its developmental risk. ${ }^{[1,2]}$

Chronic leg swelling in elderly with multiple comorbidities such as obesity, inactivity, heart failure, chronic venous hypertension that contribute to the etiology of swelling should not be excluded from prevalence studies, as it involves insufficient lymphatic drainage and also causes important morbidity. However, it should be kept in mind that existing comorbid conditions are also risk factors for LE and may occur simultaneously and further blur the clinical picture (Figure 1). In the Clinical Etiologic Anatomic Pathophysiologic (CEAP) classification, C3 category for chronic venous disease (CVD) is extensive and excludes subcategories of potentially significant edema, does not measure the degree/extent of edema or identify other etiologies of limb edema, fails to identify the degree of associated stiffening (i.e., soft vs. hard), and does not precisely define phlebolymphedema. ${ }^{[3,10,11]}$ It may be difficult to clinically distinguish whether the existing edema is due to the increased lymph burden secondary to the increase in venous hydrostatic pressure or to the existing pathology in the lymphatic system. Moreover, this cause-effect relationship may become more complex, when two separate pathophysiological processes coexist. This conclusion can be made for the primary LE tarda that begins in adult life, as well as secondary LE, in which the dynamics affecting the clinicopathological process are clearer. Although chronic edema, in which venous or lymphatic drainage insufficiency cannot be clearly defined, is considered an umbrella term that also includes classical $\mathrm{LE}^{[2,4]}$ the lymphatic component of venolymphatic insufficiency is pivotal in cases such as obesity-induced LE, phlebolymphedema, immobility-related edema, lipolymphedema, edema of advanced cancer, and chronic swelling associated with hemolymphatic malformations (HLMs; e.g., KlippelTrénaunay syndrome). ${ }^{[12]}$

In the present study, focus on clinical settings where the incidence and prevalence of LE is perceived to be important, we aimed to analyze patients with chronic lower limb LE clinically, diagnostically and etiopathogenetically. To the best of our knowledge, this is the first national epidemiological study in the field of cardiovascular surgery.

\section{PATIENTS AND METHODS}

This single-center, retrospective national epidemiological study was conducted at Erciyes University, School of Medicine, Department of Cardiovascular Surgery between January 2005 and January 2020. A total of 558 patients (161 males, 397 females; median age: 43 years; range, 10 days
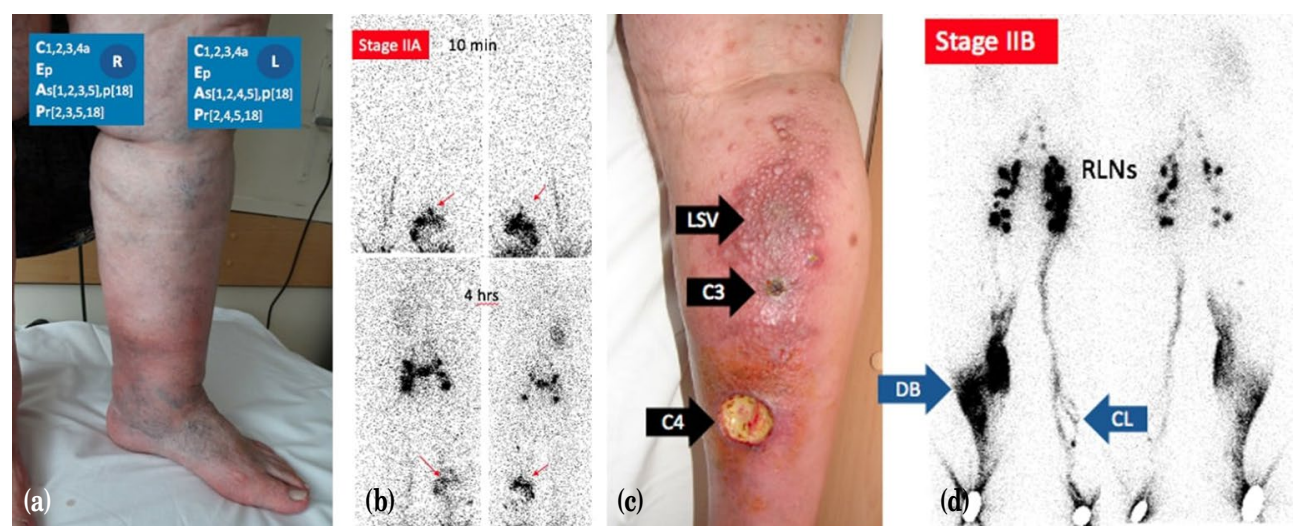

Figure 1. (a) A 69-year-old female patient with corona phlebectatica, pigmentation, edema, reticular veins, varicose veins and symptoms of skin irritation and heaviness had reflux in the great and short saphenous veins and non-saphenous vein. (b) Lymphoscintigraphy demonstrated reduced radiotracer below the expected level to regional lymph nodes and dermal back flow in the distal legs (arrows show radionuclide contamination). (c, d) A 48-year-old male patients with healed and open ulcers together with infected lymphostatic vesicles (healed and open ulcers are indicated as C3 and C4, respectively, according to the CEAP-L classification 10) The patient's legs had the appearance of an inverted champagne bottle due to widespread lipodermatosclerosis and prominent lymphedematous calf ("champagne bottle sign").

LSV: Lymphostatic vesicle; DB: Dermal backflow; CL: Collateral; RLNs: Regional lymph nodes. 
to 94 years) with chronic lower limb LE who were treated in our department were included. Patients with upper limb LE were excluded from the study. A written informed consent was obtained from each patient and/or legal guardians of the patient for the diagnostic and therapeutic procedures. The study protocol was approved by the Erciyes University, School of Medicine Clinical Research Ethics Committee (Date, no: 16.12.2020; \#2020/626). The study was conducted in accordance with the principles of the Declaration of Helsinki.

Lymphedema was classified into etiological (primary, secondary), clinical (by stage and severity), and lymphoscintigraphic, according to lymphology texts and guidelines to determine the appropriate treatment regimen and measure treatment response. ${ }^{[13-18]}$ We used the Allen classification for primary (idiopathic) LE, accepting age of onset as a criterion. ${ }^{[3,19]}$ To evaluate differently from the usual ulcers of the lower limb, ulcers with LE were specified as healed (C3) and open (C4) ulcers, according to CEAP-LE (CEAP-L) classification. ${ }^{[20]}$ Patients with truncular lymphatic malformation according to the Hamburg Classification and patients with HLMs and other malformations in which LE was a component were classified as primary LE. ${ }^{[12]}$ The pediatric age group was assumed as infancy ( $0-1$ year), childhood (2-10 years), and adolescent (11-18 years). Body mass index (BMI) was calculated for the detection and

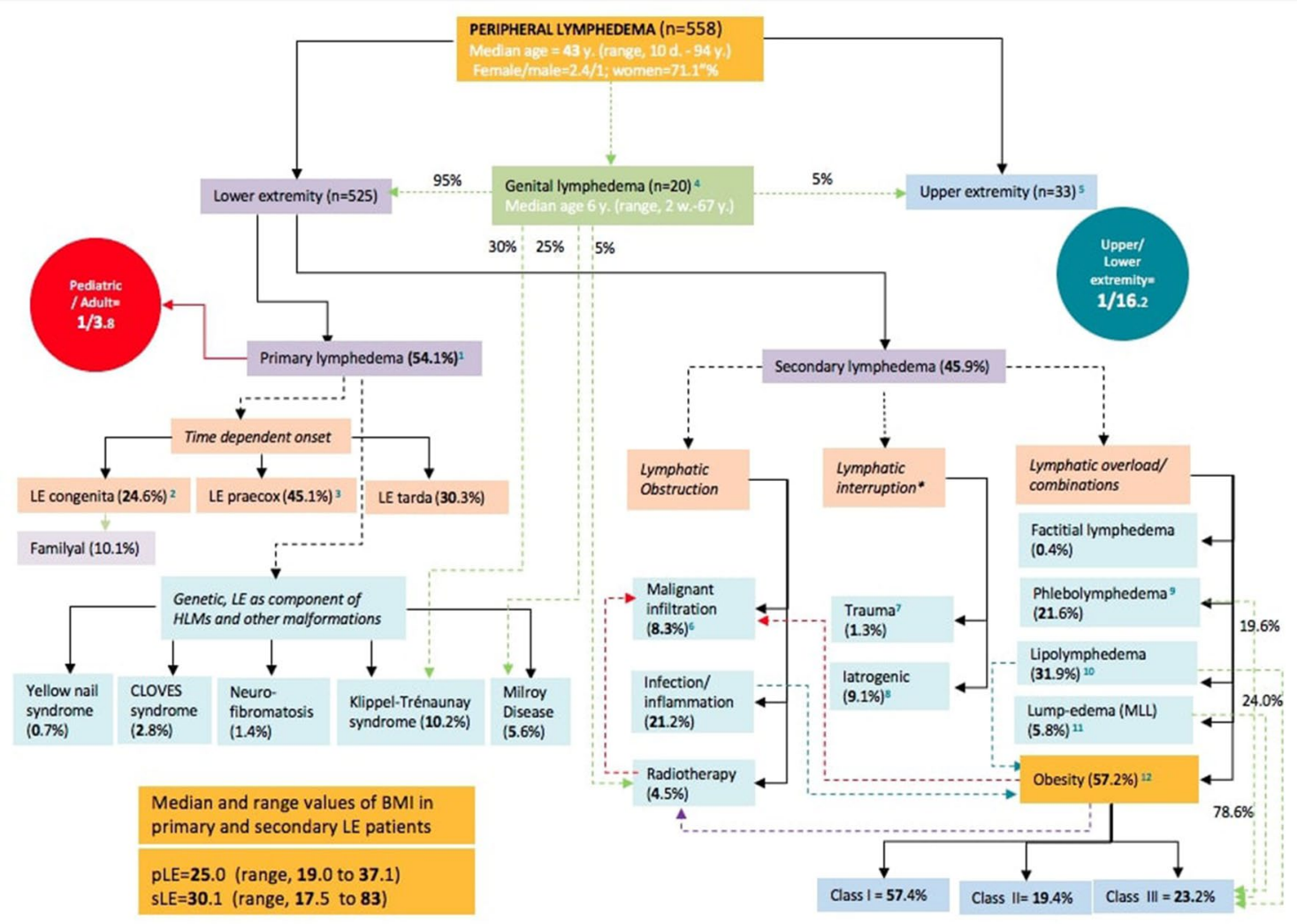

Figure 2. Algorithmic etiologic design and results. 1: Of the patients with primary LE, 33.5\% were in the pediatric age group (infancy, 34\%; childhood, 29.4\%; adolescence, 36.6\%). 2: $10.1 \%$ of the patients with congenital LE are those with familial LE. This constitutes $1.8 \%$ of the primary LE patients and $1.0 \%$ of all patients. Medical history revealed that 32 patients (45.7\%) in the lymphedema congenita group had leg swelling before the age of two years. However, these patients were over three years old at the time of admission. 3: Of the patients with LE praecox, 43.4\% were in the pediatric age group. 4: The rate of genital LE was 3.8\% and 2/3 of them were in pediatric patients. 5: Isolated upper limb, total number, which is together with lower limb, was 41. 6: Cervical, uterine, rectal, and scrotal malignities, etc., together with co-factors such as radiotherapy, surgery and/or obesity; 7: Blunt or penetrating, unrecognized, etc; 8: Inguinal surgery, lymphatic node resection, etc.; 9: Chronic venous disease accompanying lymphedema patients but whose pathophysiologic effect was not directly explained were not included in this number. 10: With accompanying obesity, infection, chronic venous insufficiency, and/or surgery (while 79.7\% of the patients with lipolymphedema have obesity, 31.7\% of them are morbidly [Class III] obesity); 11: massive localized LL: BMI= median, 47.5 (range, 28.1 to 83.0) $\mathrm{kg} / \mathrm{m}^{2} ; 12$ : Alone or in combination with other co-factors such as lipedema, chronic venous insufficiency, infection, surgery, tumor.

* Lymphatic interruption (trauma, iatrogenic), which is the cause of $11.0 \%$ of secondary lymphedema, was responsible for all adult cases; LE: Lymphedema; HLM: Hemolymphatic malformation; KTS: Klippel-Trénaunay syndrome; YNS: Yellow nail syndrome. 
Table 1. Characteristics of pediatric patients*

\begin{tabular}{|c|c|c|c|c|c|c|c|c|c|}
\hline \multirow[b]{2}{*}{ Age period (year) } & \multicolumn{2}{|c|}{ Sex } & \multirow[b]{2}{*}{ Total } & \multirow[b]{2}{*}{$p$} & \multirow[b]{2}{*}{ Affected limb } & \multicolumn{2}{|c|}{ Sex } & \multirow[b]{2}{*}{ Total } & \multirow[b]{2}{*}{$p$} \\
\hline & Male & Female & & & & Male & Female & & \\
\hline \multirow{2}{*}{ Infancy (0-1) } & \multirow{2}{*}{63.9} & \multirow{2}{*}{36.1} & \multirow{2}{*}{32.7} & \multirow{6}{*}{$=0.002$} & Unilateral & 8.3 & 36.1 & 44.4 & $<0001$ \\
\hline & & & & & Bilateral & 55.6 & 0 & 55.6 & $<0.001$ \\
\hline \multirow{2}{*}{ Childhood (2-10) } & \multirow{2}{*}{35.5} & \multirow{2}{*}{64.5} & \multirow{2}{*}{28.2} & & Unilateral & 19.6 & 64.5 & 83.9 & \multirow{2}{*}{$=0.003$} \\
\hline & & & & & Bilateral & 16.1 & 0 & 16.1 & \\
\hline \multirow{2}{*}{ Adolescence (11-18) } & \multirow{2}{*}{25.6} & \multirow{2}{*}{74.4} & \multirow{2}{*}{39.1} & & Unilateral & 16.3 & 74.4 & 90.7 & \multirow{2}{*}{$=0.003$} \\
\hline & & & & & Bilateral & 9.3 & 0 & 9.3 & \\
\hline
\end{tabular}

* When the pediatric patients were evaluated with the Pearson chi-square test in terms of age and sex, $63.9 \%$ of the patients in the infantile period were males, and $64.5 \%$ of the patients in infancy and $74.4 \%$ of the patients in the adolescent period were females. This difference in terms of age and sex distribution was found to be statistically significant $(\mathrm{p}=0.002)$. When pediatric patients were evaluated with the one-way ANOVA test according to age (infancy, childhood, and adolescence), sex and limb involvement (unilateral vs. bilateral), $55.6 \%$ of infants had bilateral involvement $(\mathrm{p}<0.001), 83.9 \%$ of children $(\mathrm{p}=0.003)$, and $90.7 \%$ of adolescents ( $\mathrm{p}=0.003$ ). The difference was statistically significant in terms of age, sex, and limb involvement.

classification of obesity, which is an important risk factor in LE, except for pediatric patients under two years of age. However, children who measure at the $85^{\text {th }}-94^{\text {th }}$ percentiles were considered overweight, due to the excess body fat or high lean body mass. A BMI of $5^{\text {th }}-85^{\text {th }}$ percentiles indicates a healthy weight range, while a BMI of $<5^{\text {th }}$ percentile indicates underweight. A BMI of $25.0-29.9 \mathrm{~kg} / \mathrm{m}^{2}$ indicates pre-obesity, a BMI of $30.0-34.9 \mathrm{~kg} / \mathrm{m}^{2}$ Class I obesity, a BMI of $35.0-39.9 \mathrm{~kg} / \mathrm{m}^{2}$ Class II obesity, and a BMI of $\geq 40.0 \mathrm{~kg} / \mathrm{m}^{2}$ Class III obesity.

Diagnostic tools were duplex ultrasonography, which was first used to assess and rule out venous disease, isotope lymphography (also termed lymphoscintigraphy), and/or magnetic resonance lymphangiography. Fine needle aspiration with cytological examination was performed, if malignancy was suspected.

\section{Statistical analysis}

Statistical analysis was performed using the IBM SPSS version 22.0 software (IBM Corp., Armonk, NY, USA). Descriptive data were expressed in median (interquartile range [IQR]) or number and frequency. The Pearson's chi-square and Fisher's exact tests were used for variables between data according to primary and secondary LE. One-way analysis of variance (ANOVA) test was used to determine whether there was any statistically significant difference between age, sex, and limb involvement in pediatric patients. A $p$ value of $<0.05$ was considered statistically significant.

\section{RESULTS}

Eight patients with isolated upper limb LE in the study design were excluded from the study, whereas $5.4 \%$ of pediatric patients with lower limb LE had combined upper limb disease. The ratio of involvement of upper/lower limb LE was 1/16.2. Primary LE accounted for $54.1 \%$ of the patients, and its distribution was LE congenita (24.6\%), praecox (45.1\%) and tarda (30.3\%) (Figure 2).

The pediatric patients consisted of $20.9 \%$ of the cases (infancy, 32.7\%; childhood, 28.2\%; adolescence, 39.1\%). Presentations with LE were more common in boys in infancy $(63.9 \%)$ and in girls in adolescence (74.4\%) (Table I). Unilateral LE was present in $73.6 \%$ of the pediatric patients (left, $55.6 \%$ and right, 44.4\%) and $26.4 \%$ had bilateral LE. Bilateral lower limb LE was more common in patients presenting in infancy (55.6\%) compared to in adolescence (9.3\%) (Figure 3). Unilateral lower limb LE was frequent in patients presenting in adolescence (90.7\%) with an elevation of the right side (62.8\%). Isolated genital involvement was not present in any of the pediatric patients, although it was associated with lower limb LE (10.8\%). Two-thirds of the genital LE patients were in the pediatric age group.

A total of $72.5 \%$ of the patients had unilateral lower limb LE, while $27.5 \%$ had bilateral LE including lipolymphedema. The ratio between the affected right/left sides was 1.7/2.0 (Figure 4).

The median BMI was $28.3 \mathrm{~kg} / \mathrm{m}^{2}$ for all patients except for infants under two years of age (range, 17.5 to 83.0). Among the patients whose BMI was evaluated, the obesity rate was $30.8 \%$, while the pre-obesity rate was $40.4 \%$. The rate of patients with pre-obesity and obesity versus patients with normal limits was $71.2 \%$ vs. $28.8 \%$, respectively. The median BMI of the obesity group was 32.9 (range, 30.1 to 83.0 ) $\mathrm{kg} / \mathrm{m}^{2}$. The obesity classification was Class I in $57.4 \%$, II in $19.4 \%$, and III in $23.2 \%$. While the median BMI was 29.1 (range, 18.3 to 49.9 ) $\mathrm{kg} / \mathrm{m}^{2}$ in patients with primary 


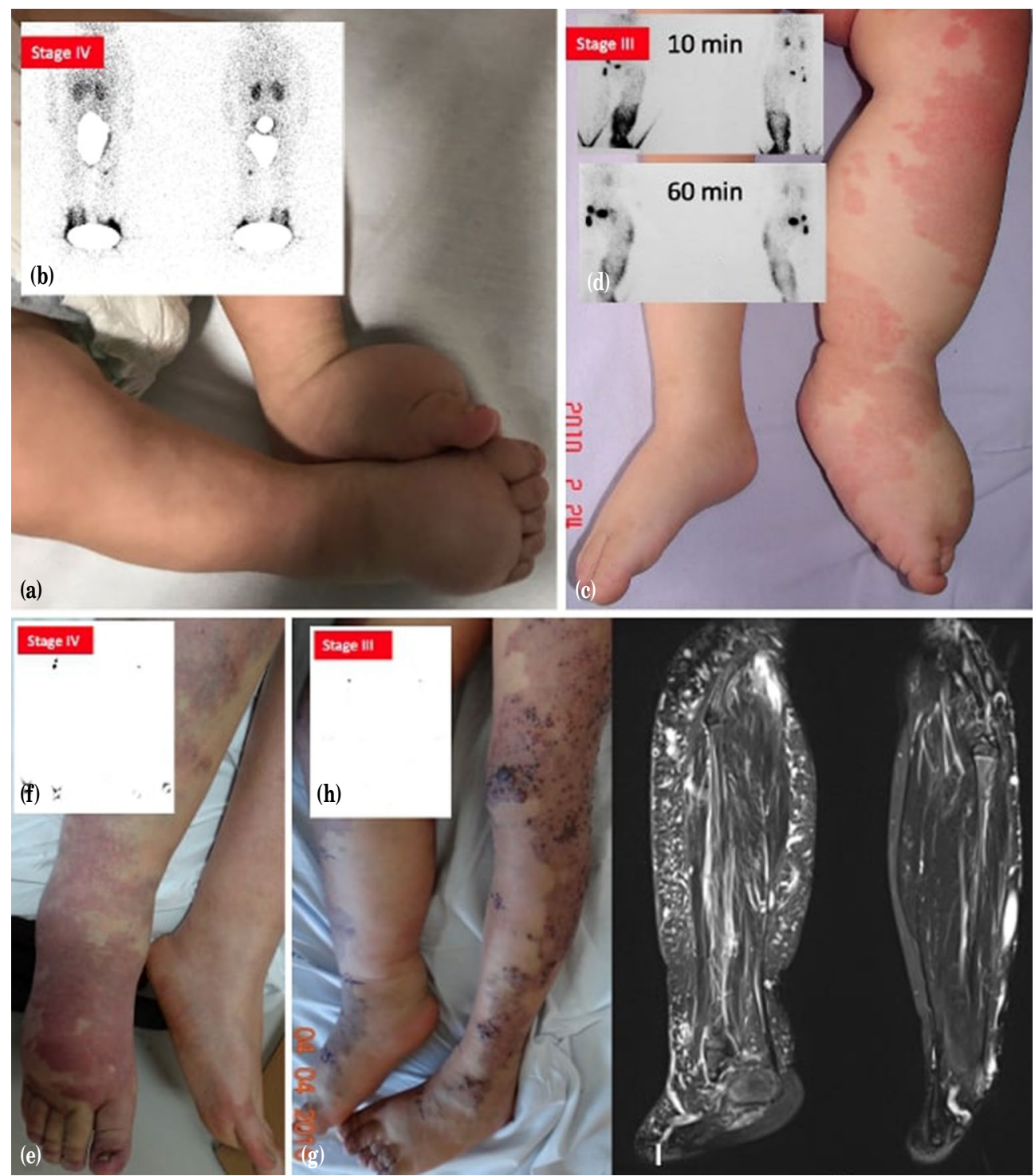

Figure 3. (a) Male infant patient with congenital lymphedema and (b) his Stage IV LSG. Note that the main lymphatics (MLs) are not visible, and DBF in the feet and ankles. (c) A pediatric patient with unilateral primary lymphedema of the lower limb as a component of KTS and (d) his Stage III LSG. Note invisible MLs and an apparent DBF. (e) A male adolescent patient with KTS and (f) his stage IV LSG with invisible MLs and poor DBF. (g) Pediatric patient with KTS and (h) her stage III LSG and (i) MRA. Note the lymphedema in the right leg, which is characterized by the appearance of honeycomb, and the lateral mega vein in the left leg in the MRA.

LSG: Lymphoscintigraphy; ML: Main lymphatic; KTS: Klippel-Trénaunay syndrome; DBF: Dermal backflow; MRA: Magnetic resonance angiography.

LE, it was 34.4 (range, 17.5 to 83.0 ) $\mathrm{kg} / \mathrm{m}^{2}$ in secondary ones.

Female patients who had children were usually multiparous and had obesity: Their median values were three (range, 2 to 7 ) for number of children, and the median BMI was 30.4 (range, 24.7 to 37.1 ) $\mathrm{kg} / \mathrm{m}^{2}$ for patients with primary LE and 33.8 (range, 28.0 to $50.8) \mathrm{kg} / \mathrm{m}^{2}$ for patients with secondary LE.
A buffalo hump appearance was present in about $29 \%$ of the patients. Bunions (hallux valgus) were present in $5.8 \%$ of the patients, and most of them were women (66.7\%) and had obesity with a median BMI of 35.1 (range, 23.1 to 83.0 ) $\mathrm{kg} / \mathrm{m}^{2}$. Two female patients (0.4\%) with right and left lower limb LE had yellow nail syndrome, and one of these patients had a juvenile bunion (Figure 5). 


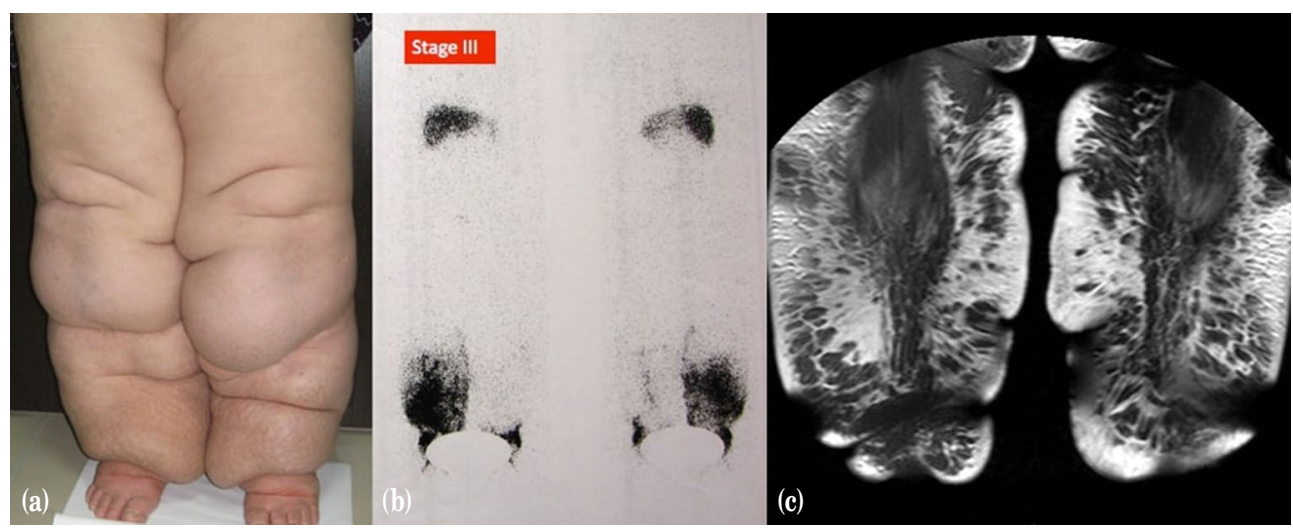

Figure 4. (a) A 47-year-old female patient with lipedema complicated by lymphedema secondary to surgery. (b) Her Stage III lymphoscintigraphy and (c) magnetic resonance lymphangiography. Note that there is no activity involvement of the lymph nodes in the areas corresponding to the inguinal, external iliac and paraaortic lymph nodes, and also large dermal backflow in the lower leg.

Seventy-seven (35.5\%) patients with lipedema were complicated with LE. While the lipedema/LE ratio was 0.27 in the same period, lipolymphedema/LE ratio was 0.14 and lipolymphedema/lipedema was 0.52 .

Twenty patients, nine of whom were infants, had genital LE (scrotal=17, labial=3). Their median age was six years (range, 2 weeks to 67 years). Genital LE accompanied by lower limb LE (bilateral $=6$, left $=7$ and right=6) was present in 19 patients, except for one upper limb. The rate of genital LE accompanying lower limb LE was 3.6\% and two-thirds of them were seen in pediatric patients.

Complications were elephantiasis (13.3\%), elephantiasis nostras verrucosa $(3.0 \%)$, cellulitis (22.1\%), erysipelas (2.3\%), ulcer (2.6\%),

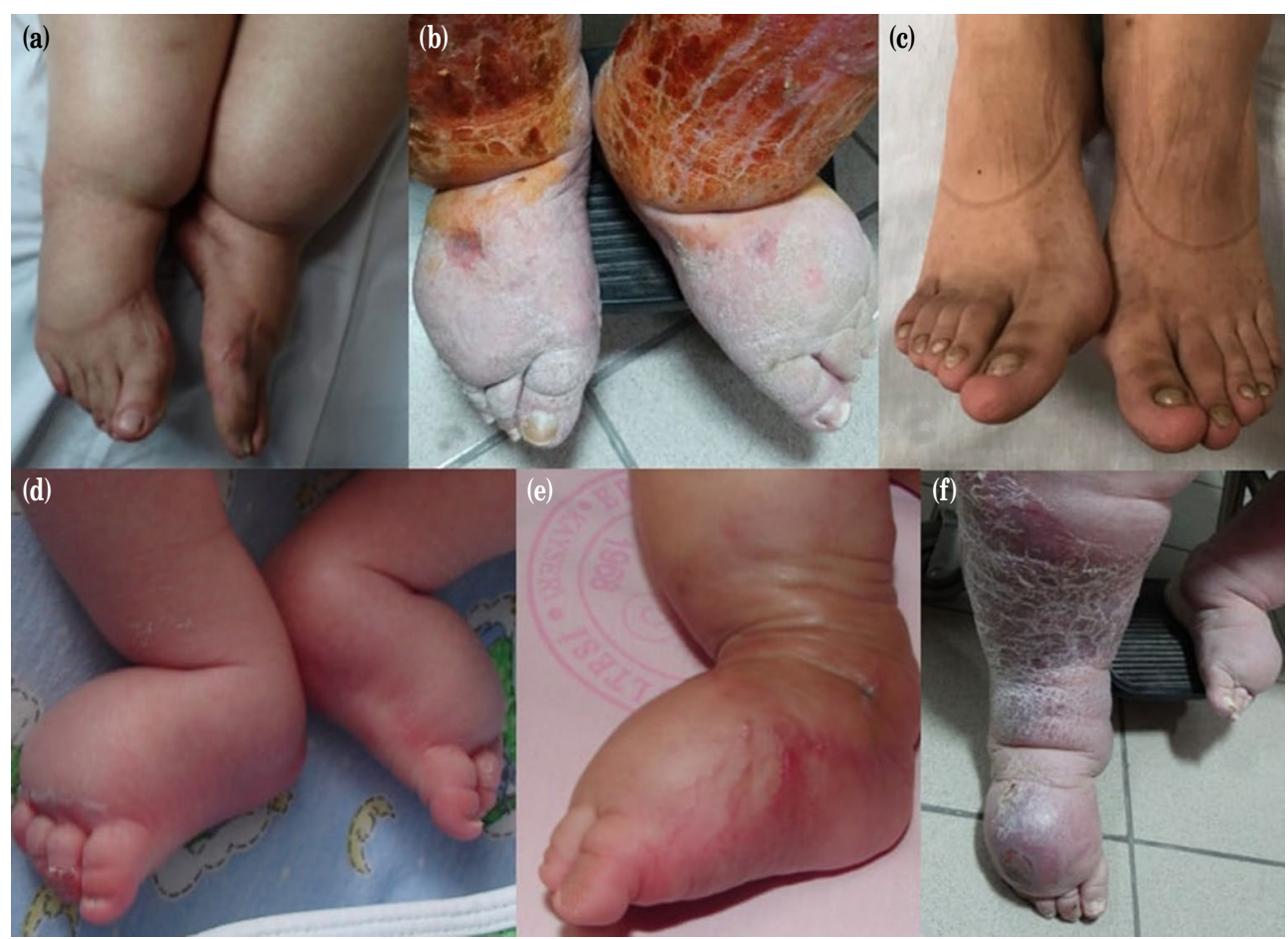

Figure 5. (a-c) Examples of patients with bunions and (d-f) typical buffalo hump among the clinical-pathological manifestations found with lymphoedema. (d) This infant with bilateral lower limb lymphedema presenting buffalo hump and koilonychia had familial congenital lymphedema (Milroy disease). (e) This infant patient with the appearance of buffalo hump and diffuse telangiectasia on the sole of the foot had hypertrichosis-lymphoedema-telangiectasia syndrome. (f) This female patient with bilateral manifest buffalo hump appearance was complicated with elephantiasis nostras verrucosa. 


\begin{tabular}{|c|c|c|c|c|c|c|}
\hline & & & PLE $(\%)$ & SLE $(\%)$ & $p$ & Total $(\%)$ \\
\hline \multirow{3}{*}{ Progression of disease } & \multicolumn{2}{|l|}{ Peau d'orange } & 0.3 & 16.1 & $<0.001$ & 6.8 \\
\hline & \multicolumn{2}{|l|}{ Elephantiasis $^{1}$} & 1.7 & 26.9 & $<0.001$ & 13.3 \\
\hline & \multicolumn{2}{|l|}{ Cellulitis ${ }^{2}$} & 10.5 & 35.7 & $<0.001$ & 22.1 \\
\hline \multirow[t]{6}{*}{ Infection } & \multicolumn{2}{|l|}{ Erysipelas } & 0.3 & 4.5 & $=0.001$ & 2.3 \\
\hline & \multicolumn{2}{|l|}{ Lymphangitis } & 1.4 & 0.4 & $=0.381$ & 0.9 \\
\hline & \multicolumn{2}{|c|}{ Lymphostatic verrucosis } & 0.3 & 2.9 & $=0.017$ & 1.5 \\
\hline & & Cosmetic deformity & 2.4 & 1.2 & $=0.356$ & 1.9 \\
\hline & \multirow[t]{2}{*}{ Lymphatic vesicles } & Bleeding & 1.0 & 0.8 & $=0.790$ & 0.9 \\
\hline & & Lymphorrhea* & 0.3 & 1.2 & $=0.338$ & 0.7 \\
\hline \multirow{4}{*}{ Skin changes } & \multicolumn{2}{|l|}{$\mathrm{ENV}^{* *}$} & 0.3 & 6.2 & $<0.001$ & 3.0 \\
\hline & \multicolumn{2}{|l|}{ Ulceration $^{3}$} & 1.0 & 5.5 & $=0.007$ & 2.8 \\
\hline & \multicolumn{2}{|l|}{ Onychomycosis } & 17.9 & 38.6 & $<0.001$ & 27.4 \\
\hline & \multicolumn{2}{|l|}{ Yellow nail syndrome } & 0.6 & - & $=0.502$ & 0.4 \\
\hline \multicolumn{3}{|c|}{ Lump-edema (MLL) } & 0.6 & 5.8 & $=0.001$ & 3.0 \\
\hline \multicolumn{3}{|c|}{ Neoplastik transformation (STS)+ } & 0.3 & - & $=0.900$ & 0.2 \\
\hline \multicolumn{3}{|c|}{ Genital lymphedema ${ }^{4}$} & 5.9 & 0.8 & $=0.002$ & 3.6 \\
\hline \multicolumn{3}{|c|}{ Difficulty fitting clothing } & 35.2 & 59.3 & $<0.001$ & 46.3 \\
\hline \multicolumn{3}{|c|}{ Difficulty using the limb (gait disturbance) } & 13.7 & 47.7 & $<0.001$ & 29.3 \\
\hline \multicolumn{3}{|c|}{ Pain/discomfort } & 40.1 & 74.7 & $<0.001$ & 56 \\
\hline \multicolumn{7}{|l|}{ Psychosocial morbidity } \\
\hline \multicolumn{3}{|c|}{ Lower self-esteem++ } & 13.7 & 47.7 & $<0.001$ & 29.3 \\
\hline \multicolumn{3}{|c|}{ Unhappiness with the appearance+++ } & 28.5 & 65.9 & $<0.001$ & 45.7 \\
\hline \multicolumn{7}{|c|}{ 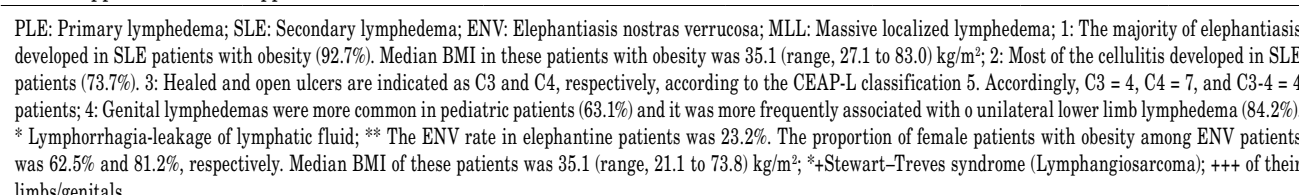 } \\
\hline
\end{tabular}

onychomycosis (27.4\%), and lymphangiosarcoma (0.2\%) (Table 2).

The rates of clinical, clinical severity, and lymphoscintigraphic staging were $11.1 \%, 38 \%$, and $28 \%$, respectively for Stage I, 55.2\%, 30.9\%, and $42 \%$, respectively for Stage II, and 33.7\%, 31.1\%, and $17 \%$, respectively for Stage III.

\section{DISCUSSION}

Most LE patients have lower limb disease with secondary LE (filariasis, inguinal lymphadenectomy and/or radiation, obesity) or primary LE (pediatric onset) worldwide. ${ }^{[2,9,13]}$ Unlike its distribution in the world, primary LE was predominant in our study (58.6\%). The fact that pediatric patients constituted one-third (19\% of all patients) of this group should have been the answer. In the pediatric patients LE emerges in infancy, adolescence, and childhood, respectively. ${ }^{[6,8]}$ In our study, the onset of $\mathrm{LE}$ in adolescence was a little more frequent than in other age periods. However, LE presentation by sex was similar (Figure 6). Lower limbs are involved in $91.7 \%$ of patients; unilateral LE is present in $50 \%$ and bilateral LE in $50 \%{ }^{[8]}$ In our study, these rates were $94.1 \%, 70.2 \%$ and $29.8 \%$, respectively. Bilateral lower limb LE was more prevalent in patients presenting in infancy compared to adolescence $(52.5 \%$ vs. $12.8 \%$, respectively).

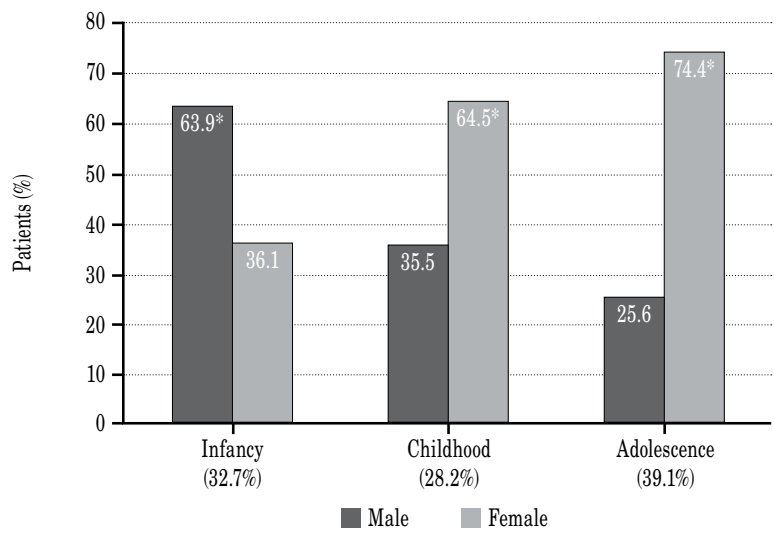

Figure 6. Age of onset of primary lymphedema in pediatric patients. $* \mathrm{p}<0.05$. 
Genetic and some comorbid factors such as obesity, infection, radiation that increase the risk of developing LE have been analyzed in numerous epidemiological studies. ${ }^{[2-6]}$ Clarifying these risk factors can be used as a way to tailor surgical methods to patients to reduce the risk of developing LE. Although the focus of LE management in developed countries is those arising from cancer treatment, more attention has been paid to LE causes other than cancer in recent years. Currently, LE due to malignancy is considered to be only a small part of the total cases. In our study, the rate of cancer-related cumulative LE was 10.1\%, together with co-factors such as radiotherapy, surgery and/or obesity. Lymphatic system injury, which accounts for about $99 \%$ of adult cases, is responsible for only $3 \%$ of pediatric diseases. ${ }^{[8]}$ In our study, lymphatic interruption (trauma, iatrogenic), which was the cause of $11.0 \%$ of secondary LE, was responsible for all adult cases.

Lymphedema may result from primary or secondary insufficient lymphatic drainage. Although edema caused by venous insufficiency is not always considered a secondary LE, CVD plus edema (i.e., CEAP: C3) has lymphatic insufficiency and is called phlebolymphedema. ${ }^{[1,3,10]}$ In our study, the median BMI of our patients with phlebolymphedema, which is among the causes of secondary LE, was 32.7 (range, 27.7 to 73.8 ) $\mathrm{kg} / \mathrm{m}^{2}$ and Class III obesity comprised about one-fifth of these cases.

Individuals with obesity (i.e., those with a BMI of $>30 \mathrm{~kg} / \mathrm{m}^{2}$ ) have more complications from LE than those of normal weight, since obesity adversely affects the lymphatic function. ${ }^{[21]}$ Obesity rate has been dramatically increasing every decade, affecting one-third of the United States population, and $6 \%$ have a BMI of $>40 \mathrm{~kg} / \mathrm{m}^{2}$. ${ }^{[22]}$ As lower limb lymphatic dysfunction can occur, patients with a BMI higher than $50 \mathrm{~kg} / \mathrm{m}^{2}$ are at a risk of developing LE due to obesity, and individuals with a BMI higher than $60 \mathrm{~kg} / \mathrm{m}^{2}$ are very likely to develop the disease. ${ }^{[21]}$ In our study, $30.8 \%$ of LE patients had obesity and $7.2 \%$ had a BMI greater than $40 \mathrm{~kg} / \mathrm{m}^{2}$, and the rate of obesity-induced lower limb secondary $\mathrm{LE}$ was about $45 \%$ alone or in combination with other co-factors such as lipedema, chronic venous insufficiency, infection, surgery, or tumor. Individuals with obesity undergoing inguinal lymphadenectomy and/or radiation are likely to be more likely to develop lower limb LE, compared to those having a normal weight. Although the mechanism by which high BMI increases the risk of post-lymphotraumatic secondary $\mathrm{LE}$ is unclear, patients with obesity may have initially compromised limb lymphatic function and, therefore, may be more prone to develop LE after receiving a second hit from lymphadenectomy and/or irradiation. Moreover, lymphatic regeneration following lymph node trauma can be also impaired by obesity. ${ }^{[23]}$ All of our LE patients who were operated and irradiated for malignancy had obesity, except for one who had pre-obesity $\left(\mathrm{BMI}=28.4 \mathrm{~kg} / \mathrm{m}^{2}\right)$, and their median BMI was $39.1 \mathrm{~kg} / \mathrm{m}^{2}$. Several factors are probably responsible for obesity-induced $\mathrm{LE}$, as secondary $\mathrm{LE}$ is difficult to cause. As the BMI increases, the amount of lymph produced by limb increases and the ambulation/muscular contraction to transport lymph fluid decreases. Moreover, excessive pressure due to tissue weight and/or progressive skin folds can collapse lymphatic channels. As can easily be seen in the algorithmic etiology of our study (Figure 1), obesity was the pivotal etiological factor of secondary LE, with almost one-fourth of which is Class III, and having complementary pathogenetic association for other reasons.

Genital LE, usually caused by inguinal lymphadenectomy and/or radiation, obesity, or primary $\mathrm{LE}$, is frequently associated with lower limb LE. Isolated genital LE is the third most prevalent location of disease ( $1 \%) .{ }^{[9]}$ In our study, the rate of genital LE associated with lower limb LE was $3.4 \%$, and primary LE caused the majority of patients $(89.5 \%)$, more than half of whom were infants (Figure 7). In general, the primary morbidity of genital LE is psychosocial, as LE patients do not like the appearance of their genital organs (Figure 7). Functional difficulties with genital (i.e., penile/scrotal) LE are rare. Uncommonly, phimosis or dysuria can occur. Genital LE does not affect sexual function or sterility. Male patients with severe genital LE may have difficulty in wearing clothing, lymphorrhea, and/or infections.

While some patients with LE continue their lives without any problems, others may have important complications ranging from decreased self-confidence to malignant transformation. Patients with more active lifestyles have fewer problems than those who are sedentary. Lymphedema is usually painless; major ailment is not consistent with the disease. If patients complain of severe pain, they probably do not have LE. Nonetheless, as the circumferential overgrowth of the limb worsens and the limb becomes heavier, the underlying musculoskeletal disorder may arise primarily due to stress on the joints. The limb may feel heavy for the patient and cause fatigue, weakness and/or paresthesia. ${ }^{[24]}$ 

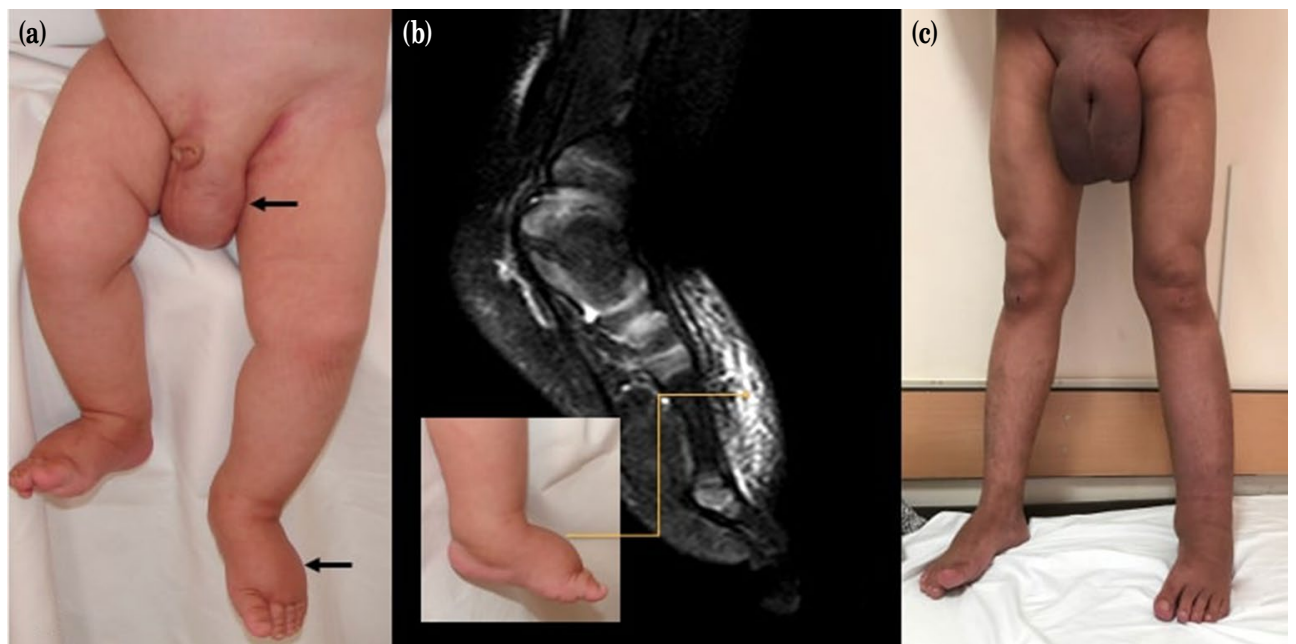

Figure 7. Examples of male patients with scrotal lymphedema associated with lower limb lymphedema. (a, b) Scrotal edema and typical buffalo hump appearance (arrows) of a one-year-old patient with bilateral lower limb lymphedema. (c) Note the radiological sign of this appearance on the patient's MRA that was previously taken at another center (elbow-arrow). (d) Accompanying scrotal lymphedema of a 22-year-old patient with unilateral (left) lower limb lymphedema.

MRA: Magnetic resonance angiography.
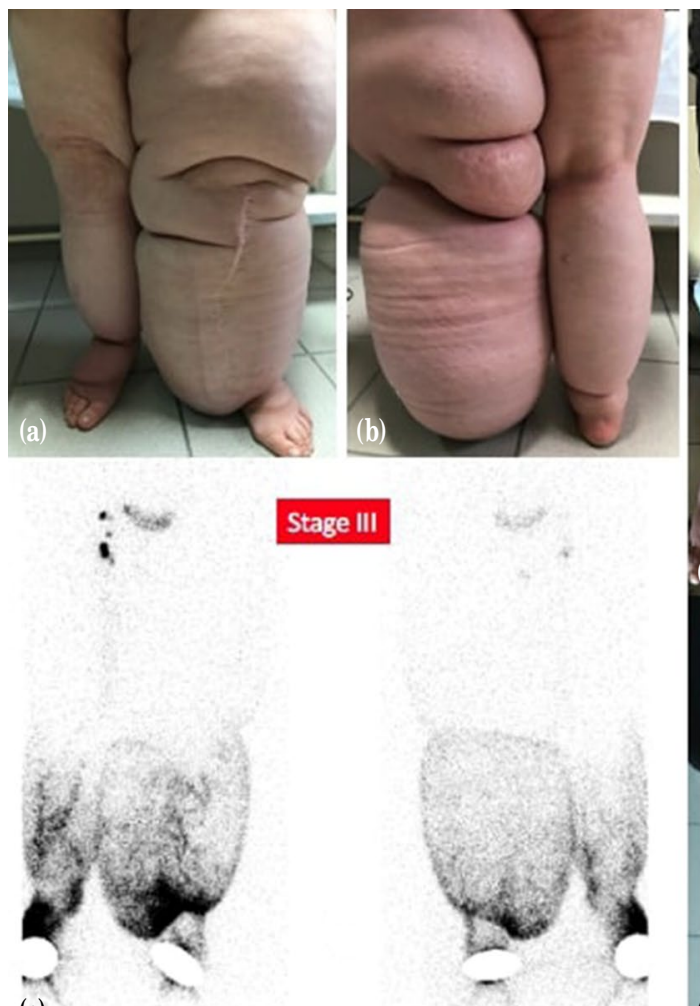

(c)
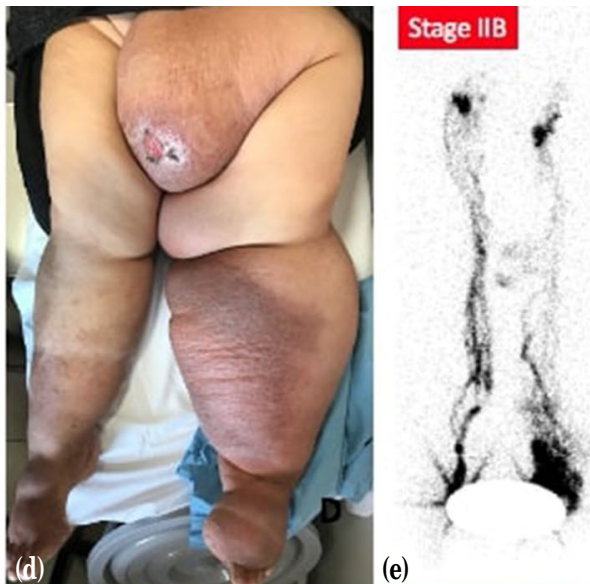

$(\mathrm{e})$

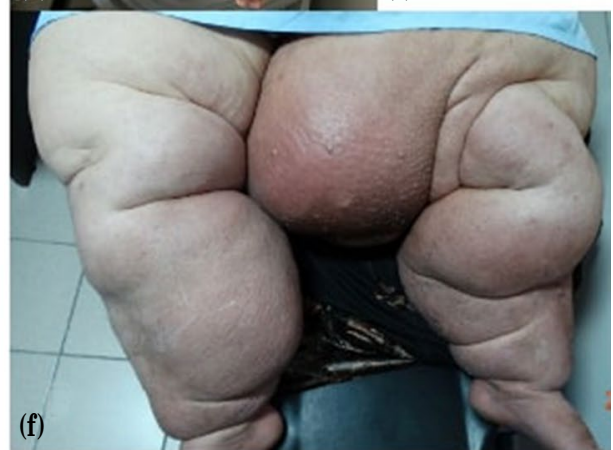

Figure 8. Massive localized lymphedema can limit ambulation. (a, b) A 66-year-old female patient with obesity $\left(\mathrm{BMI}=45.4 \mathrm{~kg} / \mathrm{m}^{2}\right)$ and adult-onset primary lymphedema had difficulty in walking due to left limb weight. (c) Her abnormal lymphoscintigram demonstrating impaired lymphatic flow, non-visualized left main lymphatic duct and dermal backflow after radiotracer injection. Note dermal backflow to be more intense in the distal calves. (d) A 48-year-old female patient with elephantine obesity $\left(\mathrm{BMI}=47.4 \mathrm{~kg} / \mathrm{m}^{2}\right)$ of Class III severity. (e) Her abnormal lymphoscintigram demonstrating impaired lymphatic flow despite visualized main lymphatic ducts. Note dermal backflow in the left leg. (f) A lymphoscintigram could not be obtained, since there would be device incompatibility depending on the weight of our 56 -year-old female patient with a BMI $=73.8 \mathrm{~kg} / \mathrm{m}^{2}$. 


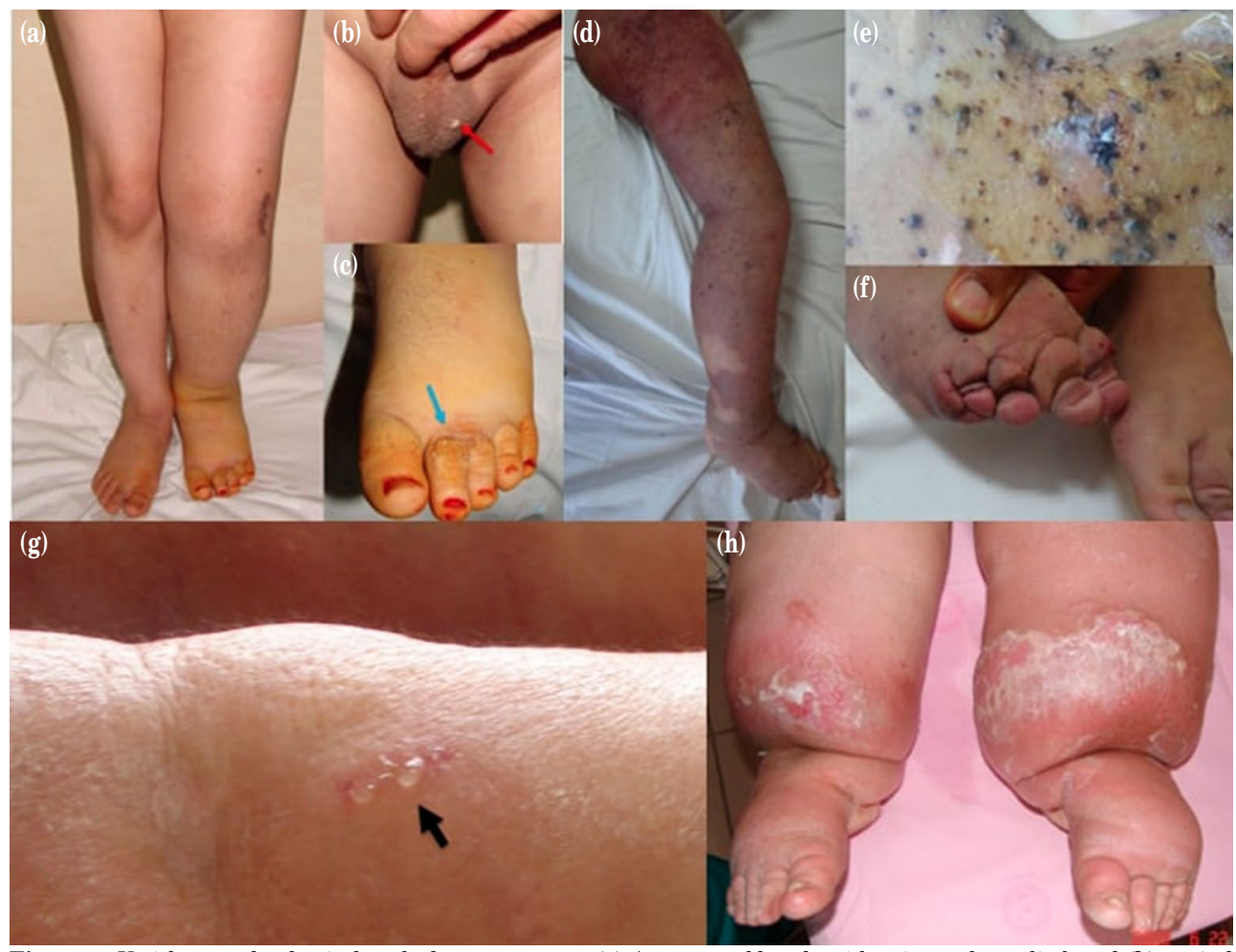

Figure 9. Vesicles can develop in lymphedematous areas. (a) A 10-year-old male with primary lower limb and (b) genital lymphedema had scrotal vesicles leaking lymph fluid (i.e., lymphorrhea) (arrow). (c) This patient, in which lymphedema also caused hyperkeratosis, had had progressive overgrowth of his second toe that has impeded his ability to wear shoes, caused pain, and leaked fluid (arrow). (d, e) A nine-year-old female with primary lower limb lymphedema as a component of hemolymphatic syndrome (Klippel-Trénaunay syndrome) had vesicles of her leg causing bleeding and multiple infections. (f) Note the deformation of the patient's toes caused by the lymphatic anomaly. (g) Examples of exudation (lymphorrhea) in lower limb LE in our two patients: minimal/"droplets" (arrow and (h) "wet"; The former is classified as (g) "S", and the latter as (h) "S2", according to the CEAP-L classification 5. (h) Note the skin epidermolysis and blistering in the last patient.

Lump-edema or massive localized LE, which develops in the limbs (particularly in the thigh), lower abdomen and genital regions (scrotal/vulvar) of men/women with obesity in the fourth or fifth decade of life, is rare and mostly affects individuals with extreme obesity (median $\mathrm{BMI}=61 \mathrm{~kg} / \mathrm{m}^{2}$ ). ${ }^{[25]}$ Although massive localized LE of the limb is typically unilateral, there is usually an underlying lymphatic dysfunction in bilateral entire limb (Figure 8). These patients may have difficulty in walking, sitting and dressing.

Although patients with LE usually have normal-appearing skin, developing dermal lymphatic vesicles can cause a cosmetic disturbance, lymphorrhea, or bleeding (Figure 9). Lymphatic leaking vesicles, which are the gateways for bacteria and can importantly increase the infectious risk, are malodorous and create psychosocial morbidity. Vesicles and hyperkeratosis most often involve the distal lower limb. ${ }^{[8,9]}$ Ulceration rarely affects LE patients, as their arterial and venous circulation is intact. Compared to the unaffected limb, an edematous limb has an importantly increased risk of cellulite. ${ }^{[6]}$ Infection, the most common functional problem caused by LE, was present in $17.6 \%$ of our patients, both as a cause and an effect (Figure 10). Cellulitis was more common in patients with LE and obesity than in patients with lipolymphedema and obesity. However, bruising was more common in the latter group of patients. ${ }^{[26]}$

Late-onset malignancies are a potentially devastating, but rare complication of long-standing secondary LE.${ }^{[3,17]}$ A rare ( 0.07 to $\left.0.45 \%\right)$, secondary, malignant tumor called lymphangiosarcoma may be the result of chronic, often massive, and long primary or secondary LE and be associated with its development (Figure 11). ${ }^{[27]}$ Classically, it refers to an angiosarcoma (or lymphangiosarcoma) that occurs in a lymphoedematous upper limb following 


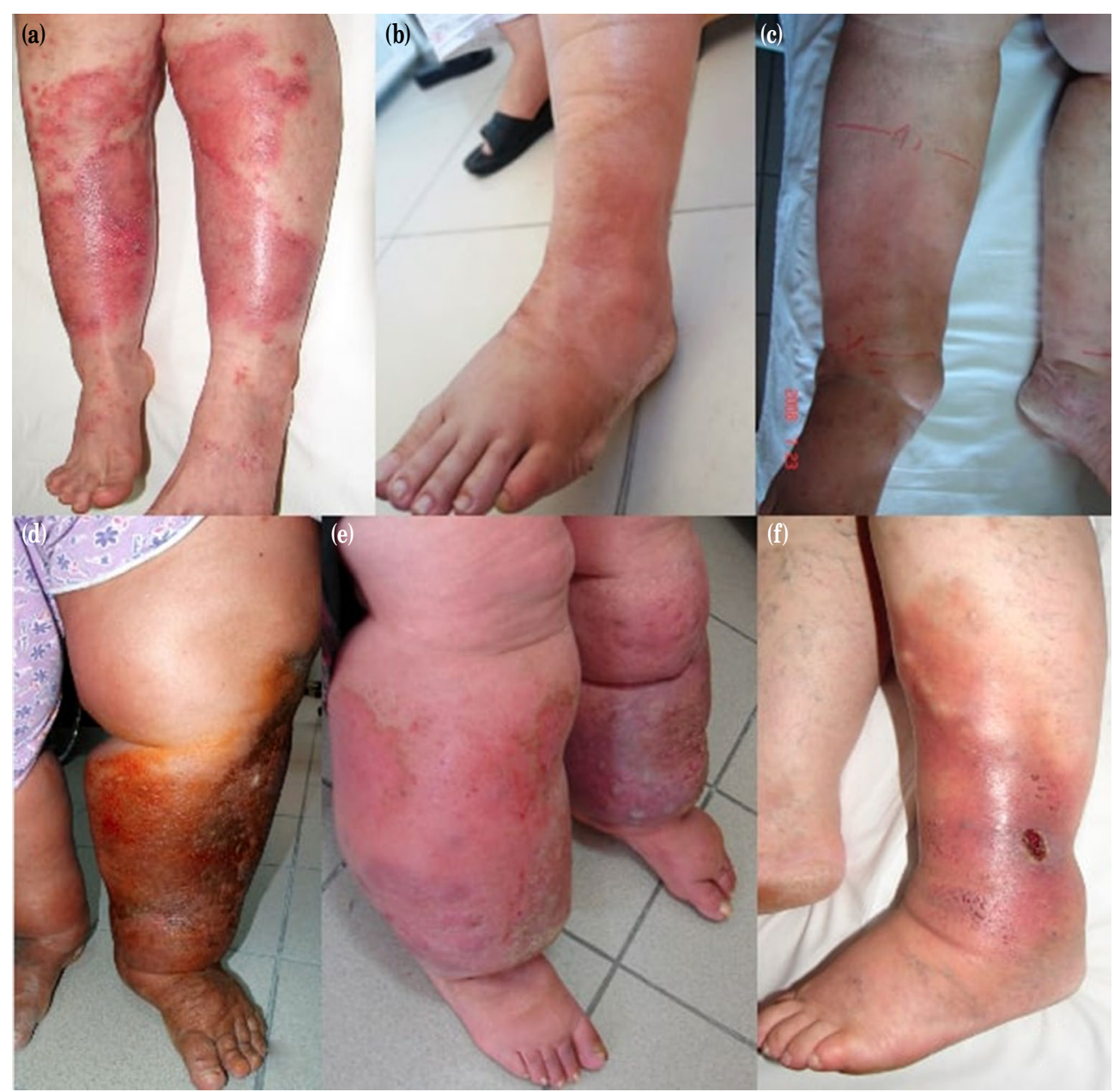

Figure 10. Lymphedematous areas are at high risk for infection. Examples of patients with lymphoedema complicated by superficial to deep skin infection: (a) Lymphangitis, (b) erysipelas, (c, d) cellulitis, (e) elephantiasis nostras verrucosa, and (f) lipolymphedema with healing ulcer and remarkable cellulitis.

breast cancer treatment. Currently, in the setting of LE, the occurrence of one of these two sarcomas, which is difficult to distinguish from each other histologically and clinically, is often called StewartTreves syndrome, although it is not a syndrome. It can also develop in chronic lower limb LE caused by inguinal lymphadenectomy and/or radiation, or lump-edema regions. ${ }^{[25,27]}$ The prognosis is poor, due to pulmonary metastasis or local recurrence. If there is no metastasis, long-term survival can be achieved with early amputation. The effectiveness of chemotherapy and radiation is minimal. Survival after diagnosis is about less than two years. ${ }^{[27]}$

Yellow nail syndrome, a triad of yellowish colored, dystrophic nails, primary LE, and pleuropulmonary manifestations, is a rare clinical entity. Syndrome develops in early middle age in most patients; however, it has also been observed in children (Figure 12).
While the cause of yellow nail syndrome is uncertain, impaired lymphatic drainage appears to be involved in the pathogenesis. ${ }^{[28]}$

Factitious LE is a dermal condition caused by wrapping an elastic bandage or cord around a leg and/or keeping the leg in a dependent and immobile state. ${ }^{[29]}$ One of our patients had a factitial LE $(\sim 0.2 \%)$ (Figure 13).

The social well-being, body image and sexuality of patients with LE who are dissatisfied with the appearance of their limbs or genitals have been adversely affected with decreased self-esteem (Figure 14). ${ }^{[6,9,30]}$ Inability to wear suitable clothing is a frequent complaint of LE patients. Patients with severe LE have often difficulty in wearing jeans or trousers and, therefore, frequently wear oversized sweatpants. Symptoms are aggravated by the asymmetry between 


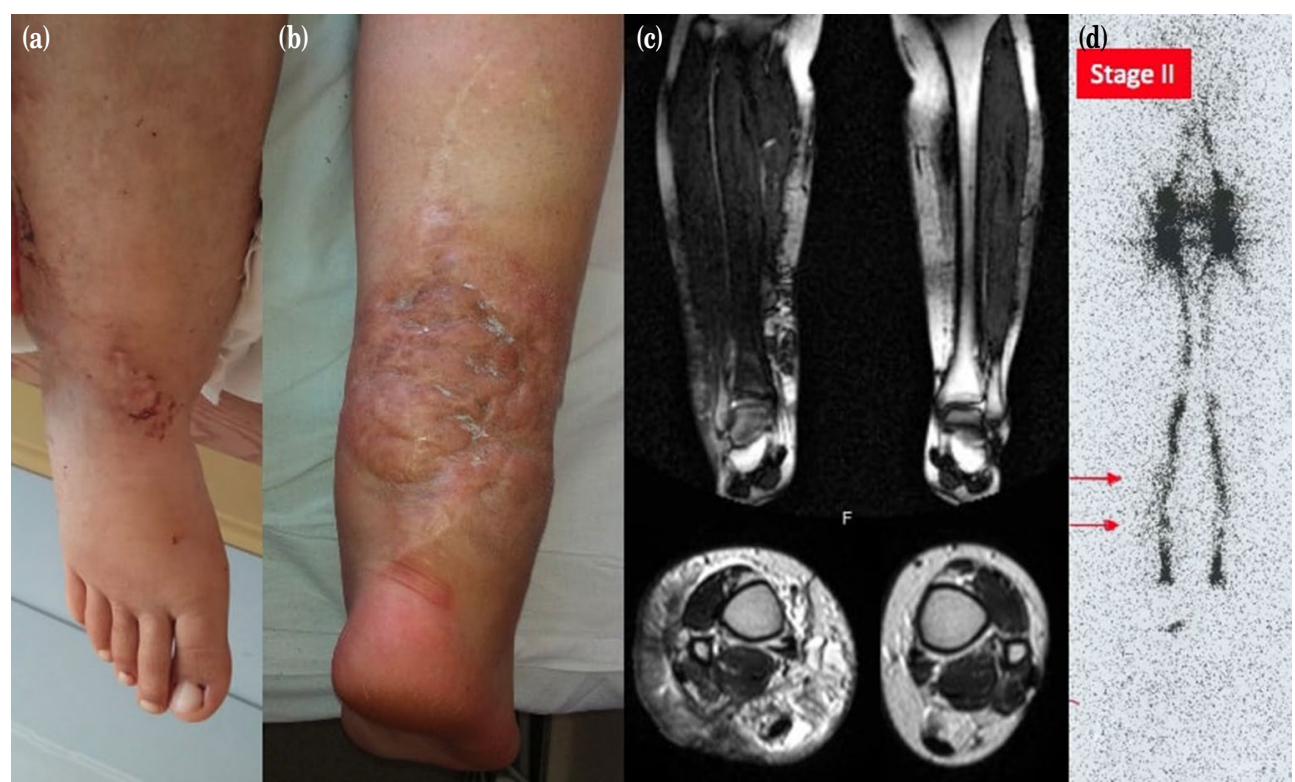

Figure 11. A 26-year-old female patient with a history of right sural surgery was diagnosed with primary lymphedema (truncular lymphatic malformation) at the outpatient clinic. However, as the patient lived in another city, the communication of the diagnostic and therapeutic process was lost. Years later, it was founded out that the patient was managed by different treatment modalities (venolymphatic anastomosis, etc.) and underwent sub-knee amputation as the final therapeutic management for lymphangiosarcoma. Her (a, b) clinical, (c) MR and (d) LSG images. Note the partial lymphatic obstruction in late LSG images (arrows).

MR: Magnetic resonance; LSG: Lymphoscintigraphic.

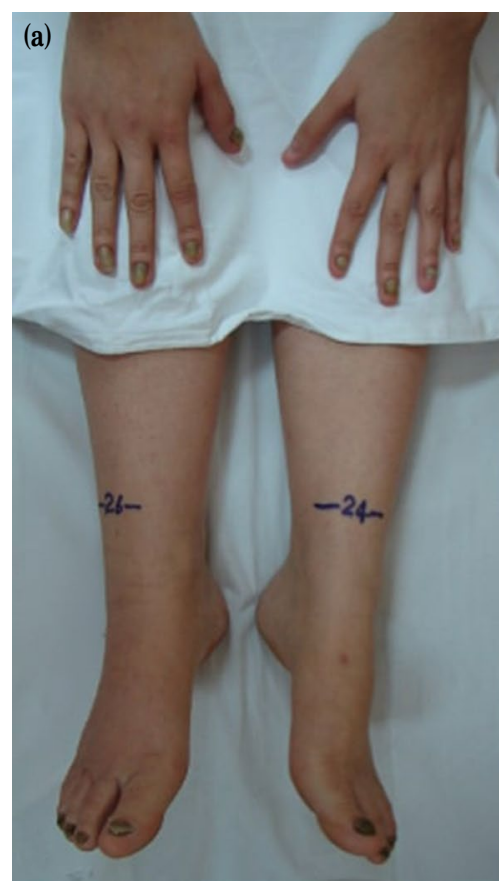

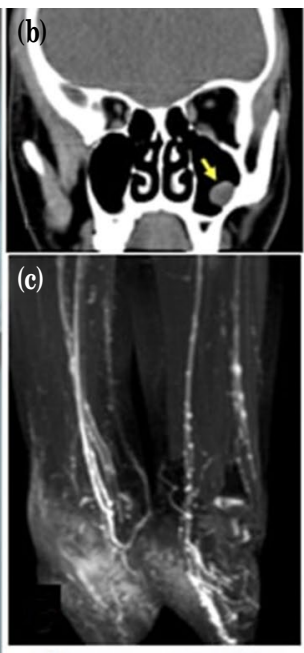

(d)

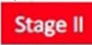

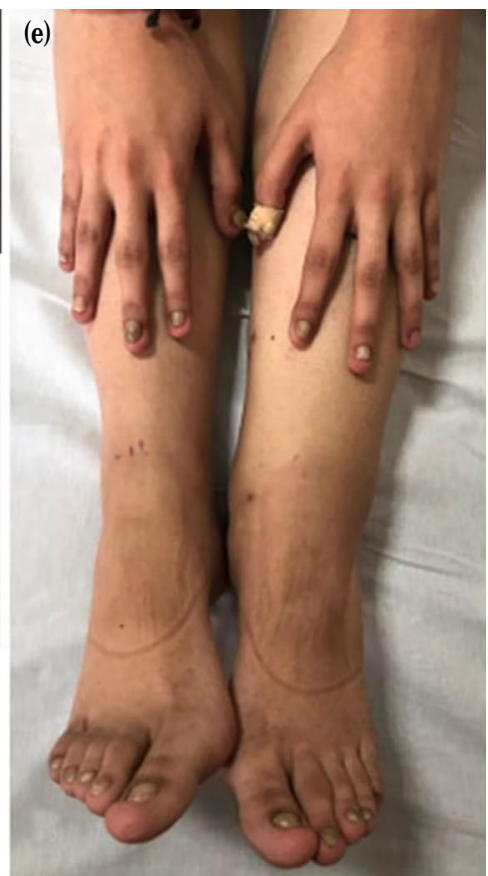

Figure 12. (a-e) Two adolescent female patients aged 17 and 14 years with yellow nail syndrome classically characterized by nail discoloration, lymphedema and pleural effusion. (b) Axial computed scan showing asymptomatic mucus retention cyst in the left maxillary sinus of the first patient with right lower limb lymphedema, and (c) magnetic resonance lymphangiography demonstrating dilated lymphatic channels in the right ankle and (c) lateral thigh of the same patient. Note the bunions of the second patient with left lower limb lymphedema. 


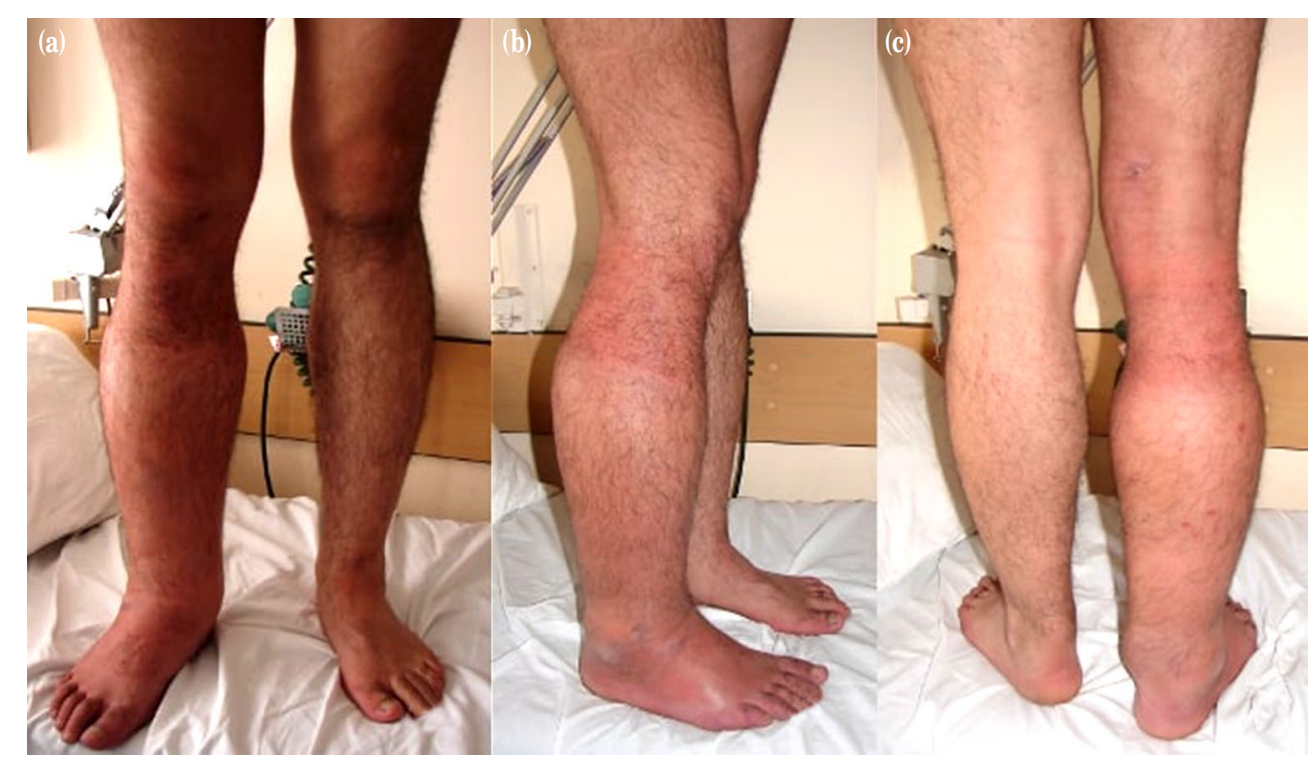

Figure 13. In a 30-year-old male patient, Class III factitial lymphedema caused by an elastic bandage wrapped around his right lower leg. Note the manifest bandage mark just below the knee and the discoloration that becomes more apparent at the ankle. (a) Anterior, (b) lateral and (c) posterior appearances.

the limbs, when the person has a unilateral disease (Figure 15). Feet are the most problematic body sites, as patients may have to wear two different sizes of footwears or wear sandals or other open shoes.

The retrospective and single-center study design can be considered as the main limitations of this study. With the inclusion of therapeutic modalities and teratment results in the study, different perspectives could have been obtained in understanding the etiological, clinicopathological and prognostic reciprocal dynamics of the disease. Certainly, further large-scale, multi-center, multidisciplinary prospective studies would be useful to achieve all of these.

In conclusion, although it is disputed that all chronic edema should be evaluated as LE, all of the complex chronic edema types such as lipolymphedema, phlebolymphedema, obesity-related LE can be accepted as secondary LE types. It is of utmost importance in prevalence studies to use a broader term LE simultaneously to cover the complex etiology of chronic leg swelling. Clinically, whatever it is called, a broader consideration of the term LE should be implemented including the underlying factors that may cause swelling, as it may affect the prevention/ reduction of risk and treatment. The long-standing presence of this condition is an ominous predictor of a challenge process in which the resulting damage cannot be easily managed, and the necessary healthcare

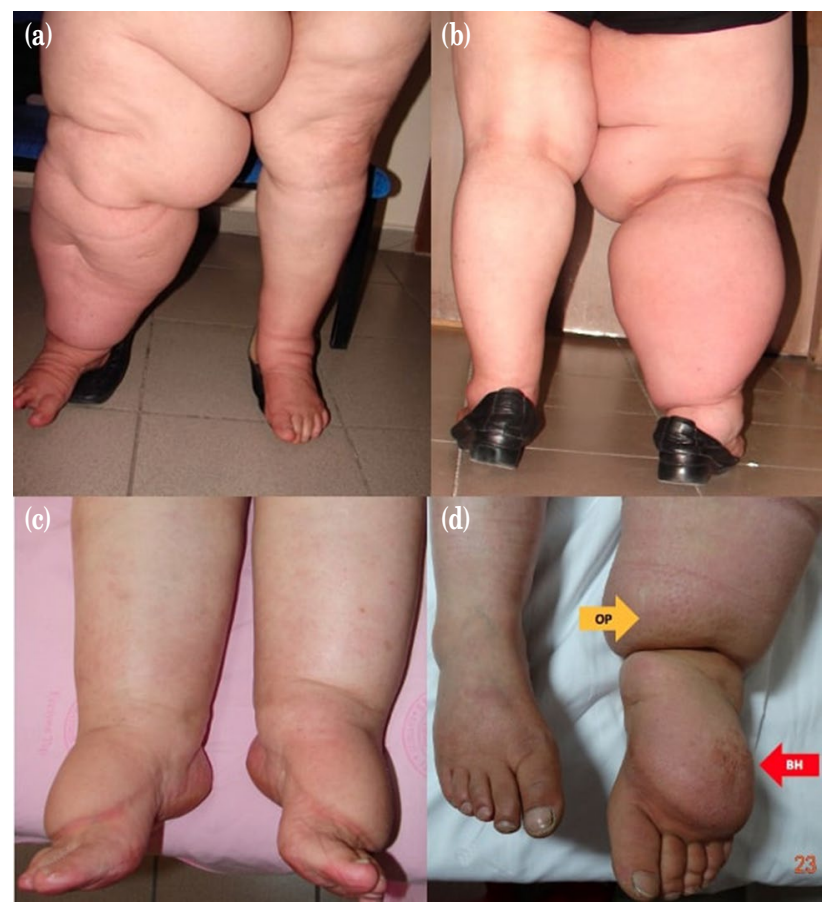

Figure 14. Psychosocial morbidity caused by lymphedema. A 40-year-old female patient with right lower limb lymphedema. $(\mathbf{a}, \mathbf{b})$ She had lowered her self-esteem, as she was not satisfied with the appearance of her diseased limb. Undoubtedly, the difficulties in wearing clothes and/or shoes in daily life were also factors affecting not only clinicopathological, but also psychological dynamics. (c) Note the significant imprint on the feet of the lymphedema, as in this patient. (d) Since asymmetry is more pronounced, unilateral limb involvement may be more distressing than bilateral disease. This patient complained of not being able to wear both fitting trousers and shoes.

OP: Orange peel; BH: Buffalo hump. 

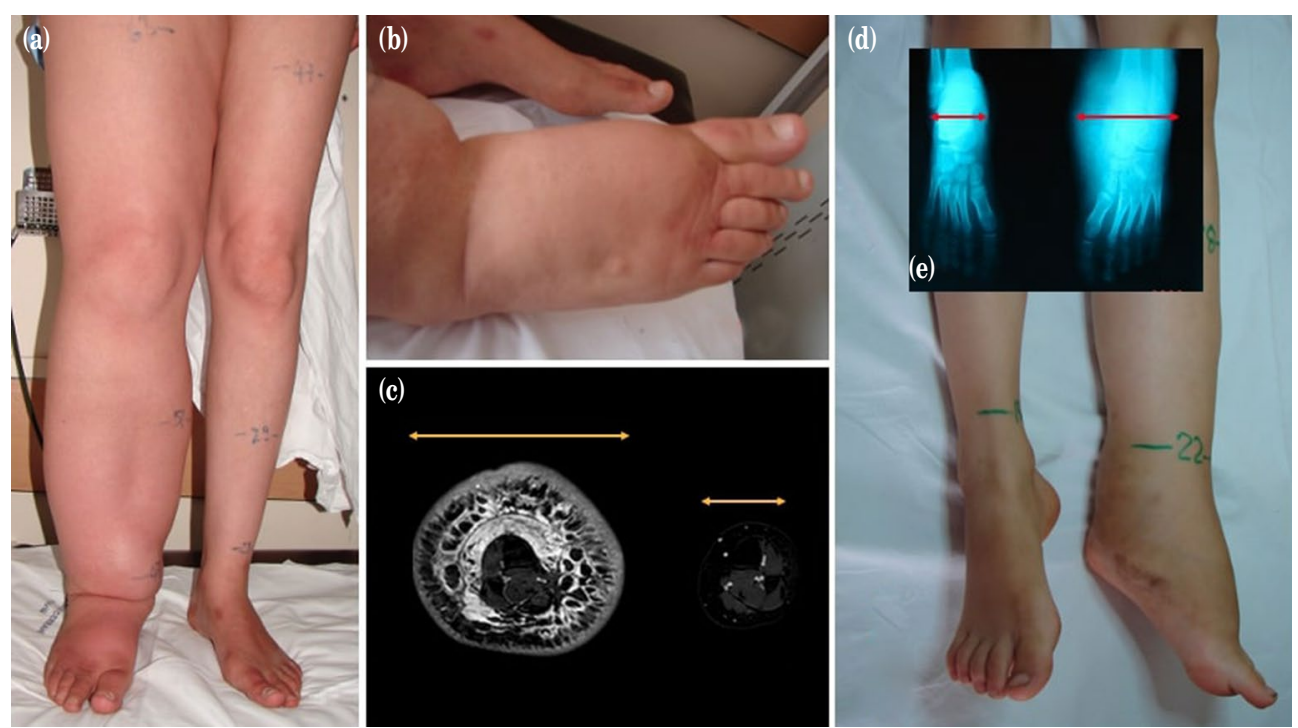

Figure 15. Our female patients, aged 20 and seven years, with pronounced lower limb lymphedema. (a-c) The first was having trouble wearing trousers, as her right leg was significantly larger than the unaffected limb. (d, e) The second patient had to wear a different size of shoes, as it was significantly larger than the unaffected foot. (c, e) Note the patients' radiological images that clearly highlight these differences.

resources would increase exponentially. If we need to use a common definition to compare the results of prevalence studies, it should be LE. The results from well-conducted trials on the impact and prevalence of the disease are crucial to convince national health authorities that LE is a widespread problem causing important morbidity and poor quality of life. In addition, results from prospective studies to objectively evaluate epidemiological data for national categories as well as the worldwide LE population would simplify future risk stratification and urge faster improving of diagnosis and treatment strategies to decrease disease burden.

\section{Declaration of conflicting interests}

The authors declared no conflicts of interest with respect to the authorship and/or publication of this article.

\section{Funding}

The authors received no financial support for the research and/or authorship of this article.

\section{REFERENCES}

1. Keeley V, Moffat C. Lymphedema epidemiology. In: Lee BB, Rockson SG, Bergan J editors. Lymphedema. 2nd ed. London: Springer International Publishing AG; 2018. p. 165-76.

2. Keast DH, Despatis M, Allen JO, Brassard A. Chronic oedema/lymphoedema: Under-recognised and undertreated. Int Wound J 2015;12:328-33.
3. Akçalı Y. Giriş: Gizemden kılavuzlara: 400 yıllık bilimsel yolculuk. Turkiye Klinikleri J Cardiovasc Surg-Special Topics 2018;10:1-9.

4. Moffatt CJ, Franks PJ, Doherty DC, Williams AF, Badger C, Jeffs E, et al. Lymphoedema: An underestimated health problem. QJM 2003;96:731-8.

5. Rockson SG, Rivera KK. Estimating the population burden of lymphedema. Ann N Y Acad Sci 2008;1131:147-54.

6. Smeltzer DM, Stickler GB, Schirger A. Primary lymphedema in children and adolescents: A follow-up study and review. Pediatrics 1985;76:206-18.

7. Williams AE, Bergl S, Twycross RG. A 5-year review of a lymphoedema service. Eur J Cancer Care (Engl) 1996;5:56-9.

8. Schook CC, Mulliken JB, Fishman SJ, Grant FD, Zurakowski D, Greene AK. Primary lymphedema: Clinical features and management in 138 pediatric patients. Plast Reconstr Surg 2011;127:2419-31.

9. Greene AK. Epidemiology and morbidity of lymphedema. In: Greene AK, Slavin SA, Brorson $\mathrm{H}$, editors. Lymphedema: Presentation, Diagnosis, and Treatment. Switzerland: Springer International Publishing; 2015. p. 33-44.

10. Farrow W. Phlebolymphedema-a common underdiagnosed and undertreated problem in the wound care clinic. J Am Col Certif Wound Spec 2010;2:14-23.

11. Rabe E, Pannier F. Clinical, Aetiological, Anatomical and Pathological Classification (CEAP): Gold standard and limits. Phlebology 2012;27 Suppl 1:114-8.

12. Akcali Y. Doğumsal vasküler malformasyonlar. In: Polat A, Akay T, Koksal C, Bozkurt AK, editörler. Damar. İstanbul: Bayçınar Tibbi Yayıncılık; 2019. s. 956-78. 
13. Executive Committee of the International Society of Lymphology. The diagnosis and treatment of peripheral lymphedema: 2020 consensus document of the International Society of Lymphology. Lymphology 2020;53:3-19.

14. Lee BB, Bergan JJ. New clinical and laboratory staging systems to improve management of chronic lymphedema. Lymphology 2005;38:122-9.

15. Bernas M. Assessment and risk reduction in lymphedema. Semin Oncol Nurs 2013;29:12-9.

16. Rooke TW, Felty CL. Lymphedema: Pathophysiology, classification, and clinical evaluation. In: Gloviczki P, Dalsing MC, Eklöf B, Lurie F, Wakefield TW, Gloviczki ML, editors. Handbook of Venous and Lymphatic Disorders. 4th ed. CRC Press; 2017. p. 707-12.

17. Rockson SG. Lymphedema: Evaluation and decision making. In: Sidawy AN, Perler BA, editors. Rutherford's Vascular Surgery and Endovascular Therapy. 9th ed. Philadelphia: Elsevier SVS. 2018. p. 7122-57.

18. Sharkey AR, King SW, Kuo RY, Bickerton SB, Ramsden AJ, Furniss D. Measuring limb volume: Accuracy and reliability of tape measurement versus perometer measurement. Lymphat Res Biol 2018;16:182-6.

19. Allen EV. Lymphedema of the extremities: Classification, etiology and differential diagnosis; A study of three hundred cases. Arch Intern Med (Chic) 1934;54:606-24.

20. Gasbarro V, Cataldi A. CEAP-L Proposal of a new classification. Eur J Lymphology 2004;12:41.

21. Greene AK, Grant FD, Slavin SA. Lower-extremity lymphedema and elevated body-mass index. N Engl J Med 2012;366:2136-7.
22. Flegal KM, Carroll MD, Ogden CL, Curtin LR. Prevalence and trends in obesity among US adults, 1999-2008. JAMA 2010;303:235-41.

23. Greene AK. Diagnosis and management of obesity-induced lymphedema. Plast Reconstr Surg 2016;138:111e-118e.

24. Brorson H, Ohlin K, Olsson G, Långström G, Wiklund I, Svensson H. Quality of life following liposuction and conservative treatment of arm lymphedema. Lymphology 2006;39:8-25.

25. Chopra K, Tadisina KK, Brewer M, Holton LH, Banda AK, Singh DP. Massive localized lymphedema revisited: A quickly rising complication of the obesity epidemic. Ann Plast Surg 2015;74:126-32.

26. Akçalı Y, Atabey RD. Lipödem ve lipolenfödem: Tanı ve tedavi. Turkiye Klinikleri J Cardiovasc Surg-Special Topics 2018;10:56-72.

27. Sharma A, Schwartz RA. Stewart-Treves syndrome: Pathogenesis and management. J Am Acad Dermatol 2012;67:1342-8.

28. Akçalı YF, Mavili E, Kula M. Yellow nail syndrome: An unsual case report. Turkiye Klinikleri J Cardiovasc Sci 2012;24:159-62.

29. De Fátima Guerreiro Godoy M, Pereira De Godoy JM. Factitious lymphedema of the arm: Case report and review of publications. Eur J Phys Rehabil Med 2015;51:337-9.

30. Fu MR, Ridner SH, Hu SH, Stewart BR, Cormier JN, Armer JM. Psychosocial impact of lymphedema: A systematic review of literature from 2004 to 2011. Psychooncology 2013;22:1466-84. 